\title{
6-Hydroxydopamine lesion of the rat prefrontal cortex impairs motor initiation but not motor execution
}

Received: 22 December 1993 / Accepted: 25 March 1994

\begin{abstract}
We examined the effects of bilateral 6-hydroxydopamine (6-OHDA) lesions of the medial prefrontal cortex (PFC) in rats on motor initiation and execution in a simple reaction time task. Reaction times (RT) and movement times (MT) were measured in trained rats on four pre- and postoperative days. Animals with 6-OHDA lesions were selectively impaired on motor initiation as measured by a significant increase in RT on each postoperative day. Motor execution was intact postoperatively, since MT was not altered. Neurochemical analysis revealed a significant depletion of prefrontal dopamine (DA) and noradrenaline (NA) in lesioned animals. It was concluded that DA and, to a lesser extent, NA in the rat PFC were involved in monitoring RT performance.
\end{abstract}

Key words Prefrontal cortex $\cdot 6$-Hydroxydopamine Dopamine $\cdot$ Noradrenaline

Reaction and movement times · Rat

\section{Introduction}

In mammals the prefrontal cortex (PFC) is defined on the basis of its reciprocal and dense connections with the mediodorsal nucleus of the thalamus (Krettek and Price 1977; Groenewegen 1988). The rat PFC receives

W. Hauber (ख)

Department of Animal Physiology,

Biological Institute, University of Stuttgart,

Pfaffenwaldring 57, D-70550 Stuttgart, Germany

M. Bubser ${ }^{1}$ - W.J. Schmidt

Department of Neuropharmacology,

Zoological Institute, University of Tübingen,

Mohlstr. 54/1, D-72074 Tübingen, Germany

${ }^{1}$ Present address:

Netherlands Institute for Brain Research,

Meibergdreef 33, 1105 AZ Amsterdam Z0,

The Netherlands cortical afferents which arise in secondary sensory areas, motor areas and paralimbic cortices (van Eden et al. 1992), and it projects to various cortical and subcortical structures, e.g. midbrain, nucleus accumbens (ACC) and anteromedial striatum (Leonard 1969; Beckstead 1979; Sesack and Pickel 1992). Furthermore, the PFC receives a dopaminergic innervation from mesocortical dopamine (DA) cells (Björklund and Lindvall 1984) and DAergic axon terminals exhibit synaptic contacts mainly with pyramidal neurons in deeper cortical layers (Verney et al. 1990). Besides, there exists a noradrenergic innervation which originates in the locus coeruleus and projects particularly to the superficial cortical layers (Swanson and Hartman 1975).

Depletion of prefrontal DA produces locomotor hyperactivity and deficits in delayed alternation tasks in rats (Carter and Pycock 1980; Simon and LeMoal 1984; Bubser and Schmidt 1990) and primates (Brozoski et al. 1979). Therefore prefrontal DA has been implicated in the control of motor and cognitive functions. While behavioural functions of the primate PFC and the role of prefrontal DA have been intensively investigated in various motor tasks (e.g. Sawaguchi et al. 1986, 1990; Boussaoud and Wise 1993), little is known about the role of prefrontal DA in rodents in more complex motor tasks. This may also be of interest in view of marked anatomical differences of the cerebral DAergic innervation between rodents and primates (Berger et al. 1991). Therefore we investigated the effects of prefrontal 6-hydroxydopamine (6-OHDA) lesions in rats trained in a simple reaction time (RT) task. The task allows measurement of movement time (MT) and RT (Hauber 1990; Hauber and Schmidt 1990) and thus examination of lesion effects on motor initiation and execution as well.

\section{Materials and methods}

Subjects

Male Sprague-Dawley rats (Interfauna, Tuttlingen, Germany), weighing $215-245 \mathrm{~g}$ at the time of surgery, were housed in groups 
of four to five animals in a temperature-controlled colony room $\left(24 \pm 2^{\circ} \mathrm{C}\right)$ with a 12 -h light-dark cycle (lights on at 6.00 a.m.). They were fed with $12 \mathrm{~g}$ of standard laboratory rat chow per animal per day (Altromin, Lage, Germany) immediately after the experiment. Water was freely available.

\section{Surgery}

One hour before surgery, rats received $40 \mathrm{mg} / \mathrm{kg}$ desipramine (Serva, Heidelberg, Germany) per os in order to protect noradrenergic terminals in the PFC from 6-OHDA neurotoxicity (Breese and Traylor 1971). Thirty minutes afterwards, the rats were injected intraperitoneally (i.p.) with promethazin $(10 \mathrm{mg} / \mathrm{kg}$; Tropon, Cologne, Germany) and 10 min later with atropine sulphate $(0.25$ $\mathrm{mg} / \mathrm{kg}$ i.p.; Serva, Heidelberg, Germany). They were anaesthetized by an i.p. injection of a mixture of ketamine $(40 \mathrm{mg} / \mathrm{kg}$; ParkeDavis, Munich, Germany) and xylazine $(2.7 \mathrm{mg} / \mathrm{kg}$; Bayer, Leverkusen, Germany), and stereotaxic surgery was carried out as described previously (Bubser and Schmidt 1990). Infusions were made at the following coordinates with respect to bregma: $\mathrm{AP}+3.0 \mathrm{~mm}, \mathrm{~L} \pm 0.8 \mathrm{~mm}, \mathrm{~V}+5.5$ and $+6.5 \mathrm{~mm}$ above the interaural line (incissor bar $3.3 \mathrm{~mm}$ below interaural line). At each injection site $1.0 \mu \mathrm{l}$ vehicle (physiological saline containing $0.1 \mathrm{mg}$ ascorbic acid/ml) or 6-OHDA $\mathrm{HBr}(6 \mu \mathrm{g} / \mu \mathrm{l})$ was infused over a period of $4 \mathrm{~min}$. After each injection, the cannula remained in place for $1 \mathrm{~min}$ in order to allow for diffusion of solution. Rats were given 12 days to recover before their postoperative performance was tested.

Tissue dissection and high-pressure liquid chromatography analysis

Nineteen days after surgery, animals were killed by decapitation. Their brains were rapidly removed from the skull, and the medial $\mathrm{PFC}, \mathrm{ACC}$, anterior striatum and posterior striatum were rapidly dissected and analysed for their contents of biogenic amines and their metabolites by HPLC with electrochemical detection (Kilpatrick et al. 1986; for details see Bubser et al. 1992).

Table 1 Effects of 6-hydroxydopamine (6-OHDA) lesion of the prefrontal cortex in rats ( $n=9$ per group) on tissue levels of biogenic amines and some of their metabolites in prefrontal cortex,

\section{Apparatus}

The experiments were carried out in a modified runway made of transparent perspex, as previously described (Hauber 1990; Hauber and Schmidt 1990). In brief, the apparatus consisted of a start box and a runway terminating in a goal box. The entrance to the runway was lockable by a remote-controlled guillotine door situated between start box and runway. The entrance was monitored by an infrared photocell beam (resolution $<10 \mathrm{~ms}$; IDEC, Hamburg, Germany) horizontally mounted directly behind the guillotine door. A combined light $(10 \mathrm{~W})$ and tone $(8 \mathrm{kHz}, 40 \mathrm{~dB})$ stimulus signalled the simultaneous opening of the front door. Below the start box a force platform was mounted which enabled a measurement of forces that an animal emitted during an operant response. The synchronous stimulus presentation and opening of the front door was controlled by a computer-operated interface (type 1401; Cambridge Electronic Design, Cambridge, UK). This device was also used as analogue-digital (A/D) converter for sampling of the force transducer output and photobeam signal at a rate of $1000 \mathrm{~Hz}$. RT and MT were measured from each trial. RT was defined as latency from stimulus presentation and up to photobeam interruption. Only RT in a range of 100-1000 ms (termed here as correct RT) were evaluated to exclude inadequate responses, e.g. anticipations. MT was defined as latency from RT (photobeam interruption) up to unloading of the force platform, which represents leaving of the start box.

\section{Behavioural procedure}

The rats were trained for rapid initiation of locomotion in response to the stimulus to receive a food reward (one $45-\mathrm{mg}$ food pellet; Noyes, Lancaster, UK). A food-deprived rat was placed in the start box facing the closed guillotine door, blocking the entrance to the runway. After a variable delay (3-10 s) the stimulus signalled the simultaneous opening of the front door. $A$ trained rat rapidly initiated locomotion, moved through the runway to the goal box and received the food reward in a baited cup. The rat was placed back in the start box for a new trial when the pellet was eaten or $10 \mathrm{~s}$ passed. On day 1 rats were first habituated to the baited apparatus for 10 min. From the next day on, animals were trained in one session per day. Each session consisted of ten successive trials. When rats had learned the task, i.e. reached a criterion of ten correct trials (RT between 100-1000 ms), their preoper-

nucleus accumbens, anterior striatum and posterior striatum. ( $D A$, dopamine, DOPAC dihydroxyphenylacetic acid, $N A$ noradrenaline, 5- $H T$ serotonin, 5-HIAA hydroxyindole-acetic acid)

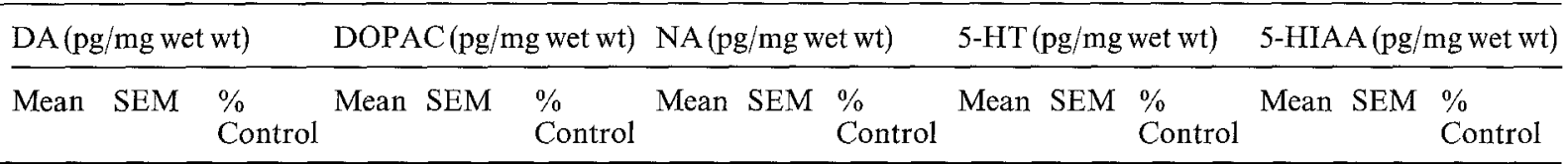

\begin{tabular}{|c|c|c|c|c|c|c|c|c|c|c|c|c|c|c|}
\hline \multicolumn{15}{|c|}{ Prefrontal cortex } \\
\hline $\begin{array}{l}\text { Vehicle } \\
\text { 6-OHDA }\end{array}$ & $\begin{array}{r}127 \\
16\end{array}$ & $\begin{array}{l}7 \\
2 * * *\end{array}$ & 12 & $\begin{array}{l}59 \\
16\end{array}$ & $\begin{array}{l}7 \\
2^{* * *}\end{array}$ & 28 & $\begin{array}{l}496 \\
116\end{array}$ & $\begin{array}{l}24 \\
19^{* * *} \quad 23\end{array}$ & $\begin{array}{l}651 \\
401\end{array}$ & $\begin{array}{l}43 \\
55^{* *}\end{array}$ & 62 & $\begin{array}{l}625 \\
521\end{array}$ & $\begin{array}{l}37 \\
47\end{array}$ & 83 \\
\hline \multicolumn{15}{|c|}{ Nucleus accumbens } \\
\hline $\begin{array}{l}\text { Vehicle } \\
\text { 6-OHDA }\end{array}$ & $\begin{array}{l}8851 \\
8532\end{array}$ & $\begin{array}{l}279 \\
925\end{array}$ & 96 & $\begin{array}{l}1979 \\
1758\end{array}$ & $\begin{array}{l}120 \\
185\end{array}$ & 90 & $\begin{array}{l}\text { ND } \\
\text { ND }\end{array}$ & & $\begin{array}{l}707 \\
976\end{array}$ & $\begin{array}{l}43 \\
92^{*}\end{array}$ & 138 & $\begin{array}{l}613 \\
604\end{array}$ & $\begin{array}{l}53 \\
38\end{array}$ & 99 \\
\hline \multicolumn{15}{|c|}{ Anterior striatum } \\
\hline $\begin{array}{l}\text { Vehicle } \\
\text { 6-OHDA }\end{array}$ & $\begin{array}{l}12078 \\
12500\end{array}$ & $\begin{array}{l}424 \\
836\end{array}$ & 104 & $\begin{array}{l}1744 \\
1624\end{array}$ & $\begin{array}{l}118 \\
125\end{array}$ & 93 & $\begin{array}{l}\text { ND } \\
\text { ND }\end{array}$ & & $\begin{array}{l}319 \\
594\end{array}$ & $\begin{array}{r}57 \\
218\end{array}$ & 186 & $\begin{array}{l}402 \\
647\end{array}$ & $\begin{array}{r}63 \\
177\end{array}$ & 122 \\
\hline \multicolumn{15}{|c|}{ Posterior striatum } \\
\hline $\begin{array}{l}\text { Vehicle } \\
\text { 6-OHDA }\end{array}$ & $\begin{array}{l}8452 \\
8549\end{array}$ & $\begin{array}{l}952 \\
101\end{array}$ & 101 & $\begin{array}{l}1322 \\
1268\end{array}$ & $\begin{array}{l}115 \\
183\end{array}$ & 96 & $\begin{array}{l}\text { ND } \\
\text { ND }\end{array}$ & & $\begin{array}{l}432 \\
550\end{array}$ & $\begin{array}{l}82 \\
49\end{array}$ & 127 & $\begin{array}{l}530 \\
534\end{array}$ & $\begin{array}{l}29 \\
54\end{array}$ & 101 \\
\hline
\end{tabular}

${ }^{*} P<0.05$; ** $P<0.01$; ${ }^{* * *} P<0.0001$; significantly different from vehicle group (Students $t$-test) 
ative performance was tested on 4 successive days with one session per day. After surgery and a recovery period the animals' postoperative performance was tested under the same conditions as preoperatively.

\section{Statistics}

Only rats with 6-OHDA lesions that exhibited less than $50 \%$ depletion of prefrontal DA - with respect to the means of the controls - were not included in the statistical analyses. Data are presented as means and standard errors of the mean (SEM). RT and MT data were subjected to a two-way analysis of variance (ANOVA), with days and treatment (6-OHDA/vehicle) as factors. In case of significant differences, postoperative performance on days 1-4 was compared with preoperative performance of the respective days using Tukey's protected $t$-test. Neurochemical data were subjected to a Student's $t$-test. A $P$ value of less than 0.05 was considered to represent a significant difference.

\section{Results}

\section{Neurochemistry}

The effects of prefrontal 6-OHDA lesion on the levels of transmitters and their metabolites are summarized in Table 1. In the medial PFC, tissue levels of DA, noradrenaline (NA) and serotonin were depleted to 12,23 and $62 \%$ of controls, respectively. Prefrontal dihydroxyphenylacetic acid (DOPAC) was also reduced to $23 \%$ of controls. In subcortical structures, neither DA nor DOPAC were affected by 6-OHDA lesion, but there was a $38 \%$ increase in serotonin in the ACC.

\section{Motor initiation and execution}

As shown in Fig. 1, RT performance of rats $(n=9)$ with vehicle infusions was not altered postoperatively $(n=90$ each day; factor day, $F_{3,712}=1.79, P>0.05$; factor treatment, $F_{1,712}=0.11, P>0.05$ ). In addition MT of animals with vehicle infusions was not affected postoperatively $\left(n=90\right.$ each day; factor day, $F_{3,712}=1.39, P>0.05$; factor treatment, $F_{1,712}=0.19, P>0.05$ ).

Rats with 6-OHDA lesions $(\mathrm{n}=9)$ showed an increase in RT on each postoperative day. Two-way ANOVA revealed a significant effect of lesion $\left(F_{1.695}=44.01\right.$, $P<0.001)$ and days $\left(F_{3.695}=3.47, P<0.02\right)$. Subsequent analysis showed that RT on postlesion days 1-4 were significantly increased compared with the respective preoperative days $(P<0.05$ on all days, Tukey's protected $t$-test). In all postoperative sessions some animals failed to complete ten correct runs with $\mathrm{RT}$ in the range of $100-1000 \mathrm{~ms}$ ( $n_{\text {preop }}=90$ each day, $n_{\text {postop }}=87$ on days 1,2 and 4 , and $n_{\text {postop }}=82$ on day 3 ). Motor execution of rats with 6-OHDA lesions was not impaired postoperatively. Two-way ANOVA revealed no significant effect of treatment $\left(F_{1.695}=3.66, P>0.05\right)$, but of days $\left(F_{3,695}=4.37, P<0.005\right)$. No correlations between RT and MT from all pre- and postoperative days were found in vehicle $\left(r_{\text {preop }}=0.18, r_{\text {postop }}=0.23\right)$ and 6OHDA $\left(r_{\text {preop }}=0.07, r_{\text {postop }}=0.09\right)$ groups.
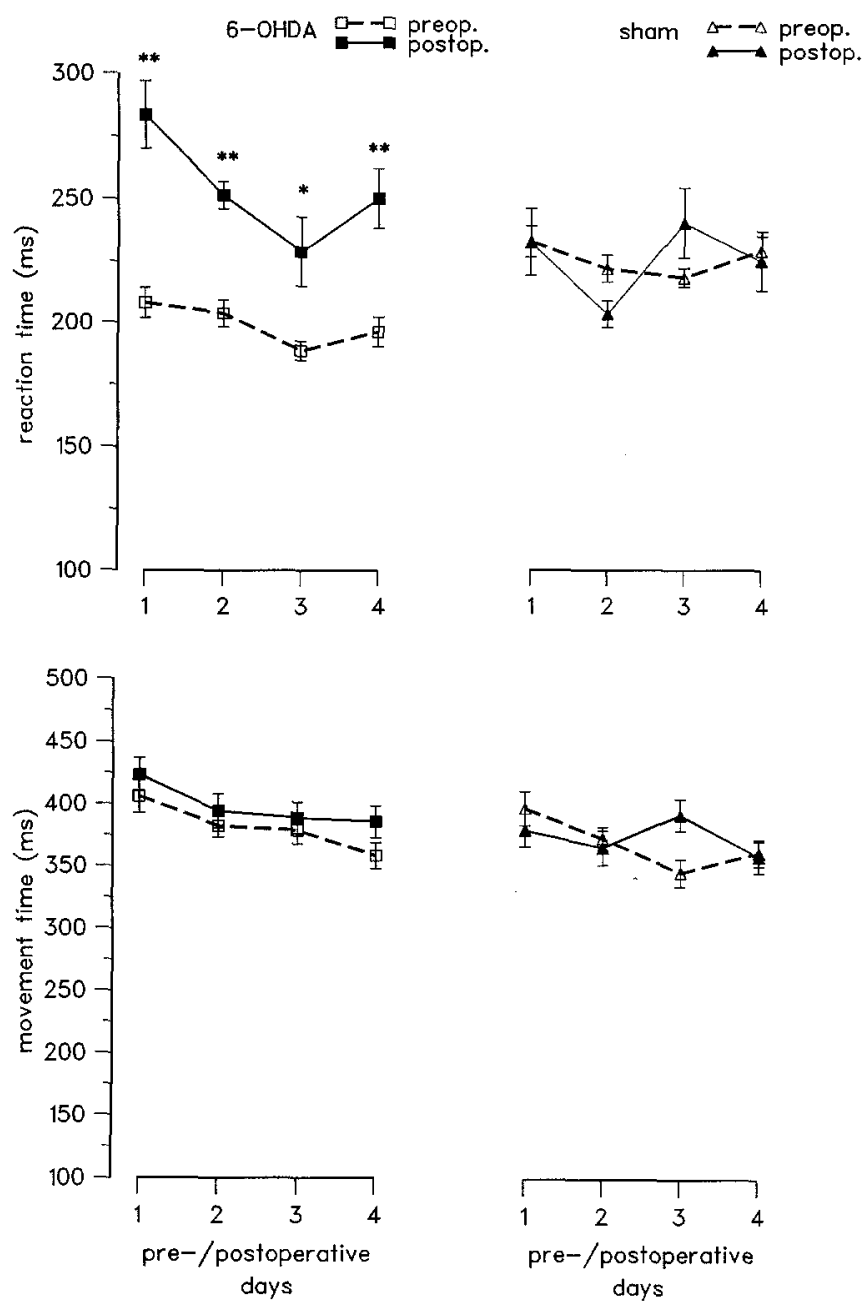

Fig. 1 Mean reaction and movement times $( \pm S E M)$ of animals tested on 4 preoperative and 4 postoperative days with one session per day consisting of ten runs per animal. Pre- and postoperative performance of animals with vehicle (sham; $n=9 ; 90$ runs per day) or 6-hydroxydopamine (6-OHD $A ; n=9 ; 82-90$ runs per day) infusions are depicted. ${ }^{*} P<0.05$; $* * P<0.01$; significant difference between pre- and postlesion reaction times (Tukey's protected $t$-test)

\section{Discussion}

The present study shows that prefrontal 6-OHDA lesions produced a significant depletion of DA and NA in the PFC and induced a postoperative impairment of motor initiation, as measured by a slowing of RT while motor execution was not affected postoperatively.

6-OHDA-induced depletion of DA was in a similar range to that shown in previous studies (Joyce et al. 1983; Clarke et al. 1988; Deutch et al. 1990; Bubser 1994). Despite pretreatment with desipramine a significant depletion of NA was also detectable, indicating a high sensitivity of the NAergic system against 6-OHDA toxicity. Although tissue levels of NA were reduced to a lesser extent than DA levels, it cannot be excluded that NA depletion contributed to the behavioural impairments of 6-OHDA-lesioned rats. In confirmation of nu- 
merous studies (Joyce et al. 1983; Clarke et al. 1988; Bubser 1994), no subcortical changes in the DAergic system could be measured. Therefore 6-OHDA-induced behavioural impairments are due to a DAergic or a combined DA/NAergic depletion within the PFC.

The lack of correlations between RT and MT in preoperatively untreated animals or postoperatively in animals with vehicle or 6-OHDA infusions support the notion that different mechanisms may be involved in motor initiation and execution (e.g. Montgomery and Buchholz 1991). Furthermore, this study shows for the first time that 6-OHDA lesions in the rat PFC selectively impaired motor initiation, while motor execution was intact in the simple RT task used here.

The role of prefrontal DA for intact delayed response performance was repeatedly shown (e.g. Simon and LeMoal 1984; Sawaguchi et al. 1986, 1990), and mesocortical DA neurons have been implicated in cognitive functions, e.g. regulation of attentional processes (Simon and LeMoal 1984). Thus, an impaired DA-dependent attentional control may be one important factor which could account for the increase in RT in the present study. The additional depletion of prefrontal NA may contribute to this impairment. However, rats with 6-OHDA lesion of the dorsal noradrenergic bundle producing an extensive depletion of neocortical NA content were unimpaired in a visual discrimination task (Cole and Robbins 1992). Thus, one may conclude that the increase in RT is predominantly caused by a disruption of the DAergic prefrontal modulation. The behavioural impairment induced by a disrupted prefrontal modulation may be mediated through cortico-striatal pathways. The anteromedial caudate-putamen (CP) receives prominent projections from the $\mathrm{PFC}$ and has been suggested to be part of a specific cortico-striatocortical functional loop (Alexander et al. 1986) mediating cognitive, i.e. complex, non-motor functions (e.g. Pisa 1988; Robbins and Brown 1990).

In contrast the lateral subregion of the $\mathrm{CP}$ and related sensorimotor cortical areas have been implicated in processing motor functions (Alexander et al. 1986). The $\mathrm{CP}$ but not the ACC has been implicated in the initiation of rapid responses, because even moderate DA depletion of the CP impaired RT performance in rats (Amalric and Koob 1987). The medial subregion of the CP seems to be important for rapid movement initiation, since neurotoxic lesions of the medial but not of the lateral CP impaired RT performance of rats in the RT task used in the present study (Hauber and Schmidt 1994) and other RT tasks (Brown and Robbins 1989). Furthermore, neurons of the medial CP were found to respond predominantly to a sensory trigger stimulus, while neurons in the lateral $\mathrm{CP}$ showed mainly response-related activity in a rat lever-release task (White and Rebec 1993). Thus the cognitive cortico-striato-cortical loop may play a role in monitoring the behavioural context for detection of relevant stimuli and is thus a prerequisite for intact RT performance. In accordance with this view, separate mechanisms underlying motor initiation and execution were suggested and the caudate nucleus was proposed to be involved in mechanisms for motor initiation (Montgomery and Buchholz 1991).

The present results have several implications: the increased RT induced by systemic administration of various DA antagonists in this (Hauber and Schmidt 1990) or other simple RT tasks for rodents (Amalric et al. 1993; Marrow et al. 1993) may not be due exclusively to an impaired DAergic transmission in the $\mathrm{CP}$ but also to a DA receptor blockade in the PFC. An involvement of prefrontal DA may be also relevant for increased RT measured in patients with Parkinson's disease (Evarts et al. 1981). In advanced stages of Parkinson's disease there is not only an impaired DA innervation of the CP but, additionally, a reduced DAergic and NAergic innervation of the cerebral cortex, which may play a role in motor (Scatton et al. 1983) and attentional processes (Stam et al. 1993).

In conclusion, the present study shows that prefrontal DA and probably to a lesser extent NA contribute to rapid motor initiation but not to motor execution in the rat. Thus not only the DAergic innervation of the CP but also prefrontal DA innervation are involved in monitoring RT.

Acknowledgements We are grateful to the expert help of A. Arnold (DipBiol) who installed the hardware and wrote the software (TurboPascal) to operate the apparatus and to perform online data evaluation. We thank Eva Wacker for excellent technical assistance. This work was supported in part by the Deutsche Forschungsgemeinschaft (SFB 307/A4)

\section{References}

Alexander GE, DeLong MR, Strick PL (1986) Parallel organization of functionally segregated circuits linking basal ganglia and cortex. Annu Rev Neurosci 9:357-381

Amalric M, Koob GF (1987) Depletion of dopamine in the caudate nucleus but not in nucleus accumbens impairs reactiontime performance in rats. J Neurosci 7:2129-2134

Amalric M, Berhow M, Polis I, Koob GF (1993) Selective effects of low-dose $\mathrm{D}_{2}$ dopamine receptor antagonism in a reactiontime task in rats. Neuropsychopharmacology 8:195-200

Beckstead RM (1979) An autoradiographic examination of corticocortical and subcortical projections of the mediodorsal-projection (prefrontal) cortex in the rat. J Comp Neurol 184:4362

Berger B, Gaspar P, Verney C (1991) Dopaminergic innervation of the cerebral cortex: unexpected differences between rodents and primates. Trends Neurosci 14:21-27

Björklund A, Lindvall O (1984) Dopamine-containing systems in the CNS. In: Björklund A, Hökfelt T (eds) Handbook of chemical neuroanatomy, vol 2. Elsevier, Amsterdam, pp 55-122

Boussaoud D, Wise SP (1993) Primate frontal cortex: effects of stimulus and movement. Exp Brain Res 95:28-40

Breese GR, Traylor TD (1971) Depletion of brain noradrenaline and dopamine by 6-hydroxydopamine. $\mathrm{Br} \mathrm{J}$ Pharmacol 42:88-99

Brown VJ, Robbins TW (1989) Elementary processes of response selection mediated by distinct regions of the striatum. J Neurosci 9:3752-3765

Brozoski TJ, Brown RM, Rosvold HE, Goldman PS (1979) Cognitive deficit caused by regional depletion of dopamine in prefrontal cortex of rhesus monkey. Science 205:929-932 
Bubser M (1994) 6-Hydroxydopamine lesions of the medial prefrontal cortex do not affect dopamine metabolism in the basal ganglia at short and long postsurgical intervals. Neurochem Res 10:421-425

Bubser M, Schmidt WJ (1990) 6-Hydroxydopamine lesion of the rat prefrontal cortex increases locomotor activity, impairs acquisition of delayed alternation tasks, but does not affect uninterrupted tasks in the radial maze. Behav Brain Res 37:157168

Bubser M, Keseberg U, Notz PK, Schmidt WJ (1992) Differential behavioural and neurochemical effects of competitive and noncompetitive NMDA receptor antagonists. Eur J Pharmacol 229:75-82

Carter CJ, Pycock CJ (1980) Behavioural and biochemical effects of dopamine and noradrenaline depletion within the medial prefrontal cortex of the rat. Brain Res 192:163-176

Clarke PBS, Jakubovic A, Fibiger HC (1988) Anatomical analysis of the involvement of mesolimbocortical dopamine in the locomotor stimulant actions of $d$-amphetamine and apomorphine. Psychopharmacology 96:511-520

Cole BJ, Robbins TW (1992) Forebrain norepinephrine: role in controlled information processing in the rat. Neuropsychopharmacology 7:129-142

Deutch AY, Clark WA, Roth RH (1990) Prefrontal cortical dopamine depletion enhances the responsiveness of mesolimbic dopamine neurons to stress. Brain Res 521:311-315

Eden CG van, Lamme VAF, Uylings HBM (1992) Heterotopic cortical afferents to the medial prefrontal cortex in the rat. A combined retrograde and anterograde tracer study. Eur J Neurosci 4:77-97

Evarts EV, Teräväinen H, Calne DB (1981) Reaction time in Parkinson's disease. Brain 104:167-186

Groenewegen HJ (1988) Organization of the afferent connections of the mediodorsal thalamic nucleus in the rat related to the mediodorsal-prefrontal topography.Neuroscience 24:379-431

Hauber W (1990) A novel reaction time task for investigating force and time parameters of locomotor initiation in rats. Experientia 46:1084-1088

Hauber W, Schmidt WJ (1990) The NMDA antagonist dizocilpine reverses haloperidol-induced movement initiation deficits. Behav Brain Res 41:161-166

Hauber W, Schmidt WJ (1994) Differential effects of lesions of the dorsomedial and dorsolateral caudate-putamen on reaction time performance in rats. Behav Brain Res 60:211-215

Joyce EM, Stinus L, Iversen SD (1983) Effect of injections of 6OHDA into either nucleus accumbens septi or frontal cortex on spontaneous and drug-induced activity. Neuropharmacology $22: 1141-1145$

Kilpatrick IC, Jones MW, Phillipson OT (1986) A semiautomated analysis method for catecholamines, indoleamines, and some prominent metabolites in microdissected regions of the nervous system: an isocratic HPLC technique employing coulometric detection and minimal sample preparation. $\mathbf{J}$ Neurochem $46: 1865-1876$
Krettek JE, Price JL (1977) The cortical projections of the mediodorsal nucleus and adjacent nuclei in the rat. J Comp Neurol 171:157-192

Leonard CM (1969) The prefrontal cortex of the rat. I. Cortical projections of the mediodorsal nucleus. II. Efferent connections. Brain Res 12:321-343

Marrow L, Overton P, Clark D (1993) Disruption of conditioned reaction time performance by dopamine receptor antagonists in the rat. Behav Pharmacol 4:15-28

Montgomery EB Jr, Buchholz SR (1991) The striatum and motor cortex in motor initiation and execution. Brain Res 549:222229

Pisa M (1988) Motor somatotopy in the striatum of rat: manipulation, biting and gait. Behav Brain Res 27:21-35

Robbins TW, Brown VJ (1990) The role of the striatum in the mental chronometry of action: a theoretical review. Rev Neurosci $2: 181-213$

Sawaguchi T, Matsumura M, Kubota K (1986) Dopamine modulates neuronal activities related to motor performance in the monkey prefrontal cortex. Brain Res 371:404-408

Sawaguchi T, Matsumara M, Kubota K (1990) Catecholaminergic effects on neuronal activity related to a delayed response task in monkey prefrontal cortex. J Neurophysiol 63:1385-1400

Scatton B, Javoy-Agid F, Rouquier L, Dubois B, Agid Y (1983) Reduction of cortical dopamine, noradrenaline, serotonin and their metabolites in Parkinson's disease. Brain Res 275:321328

Sesack SR, Pickel VM (1992) Prefrontal cortical efferents in the rat synapse on unlabeled neuronal targets of catecholamine terminals in the nucleus accumbens septi and on dopamine neurons in the ventral tegmental area. J Comp Neurol 320:145-160

Simon H, Le Moal M (1984) Mesencephalic dopaminergic neurons: functional role. In: E Usdin, A Carlsson, J Engel (eds) Catecholamines: neuropharmacology and central nervous system-theoretical aspects. Liss, New York, pp 293-307

Stam CJ, Visser SL, Op de Coul AW, De Sonneville LMJ, Schellens RLLA, Brunia CHM, Smets JS de, Gielen G (1993) Disturbed frontal regulation of attention in Parkinson's disease. Brain 116:1139-1158

Swanson LW, Hartman BK (1975) The central adrenergic system. An immunofluorescence study of the location of cell bodies and their efferent connections in the rat utilizing DA- $\beta$-hydroxylase as a marker. J Comp Neurol 163:467-506

Verney C, Alvarez C, Geffard M, Berger B (1990) Ultrastructural double-labelling study of dopamine terminals and GABAcontaining neurons in rat anteromedial cerebral cortex. Eur J Neurosci 2:960-972

White IM, Rebec GV (1993) Responses of rat striatal neurons during performance of a lever-release version of the conditioned avoidance response task. Brain Res 616:71-82 